\title{
TITLE:
}

\section{$<$ NOTE $>$ A Female Bonobo Sleeping on the Ground after Daytime Birth and its Implications}

\section{$\operatorname{AUTHOR}(S)$ :}

Ryu, Heungjin

\section{CITATION:}

Ryu, Heungjin. <NOTE>A Female Bonobo Sleeping on the Ground after Daytime Birth and its Implications. Pan Africa News 2017, 24(2): 9-13

ISSUE DATE:

2017-12

URL:

http://hdl.handle.net/2433/228899

RIGHT:

Copyright (C) Pan Africa News. 


\section{Pan Africa News}

The Newsletter of the Comm thee for the Care and Conservation of Chimpanzees and the Mahale Wild life conservation society

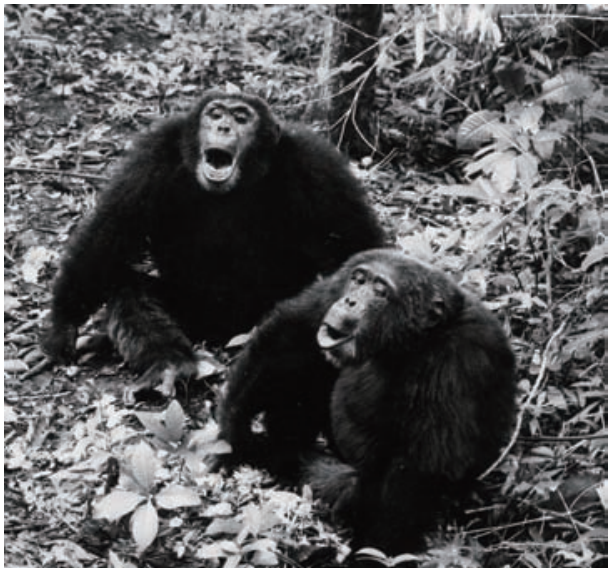

ISSN 1884-751X (print), 1884-7528 (online) mahale.main.jp/PAN/

VOL. 24, NO. 2

\section{Contents}

\section{Chief Editor:}

Kazuhiko Hosaka, Kamakura Women's University, Japan

Deputy Chief Editor:

Michio Nakamura, Kyoto University, Japan

\section{Associate Editors:}

Christophe Boesch, Max-Planck Institute, Germany

Jane Goodall, Jane Goodall Institute, USA

Tetsuro Matsuzawa, Kyoto University, Japan

William C. McGrew, University of St. Andrews, UK

John C. Mitani, University of Michigan, USA

Vernon Reynolds, Budongo Forest Project, UK

Yukimaru Sugiyama, Kyoto University, Japan

Richard W. Wrangham, Harvard University, USA

Takeshi Furuichi, Kyoto University, Japan

\section{Editorial Secretaries:}

Noriko Itoh, Kyoto University, Japan

Koichiro Zamma, Nagano College of Nursing, Japan

Eiji Inoue, Toho University, Japan

Takuya Matsumoto, Research Institute for Humanity and Nature, Japan

\section{Instructions for Authors:}

Pan Africa News publishes articles, notes, reviews, forums, news, essays, book reviews, letters to editor, and classified ads (restricted to non-profit organizations) on any aspect of conservation and research regarding chimpanzees (Pan troglodytes) and bilias (Pan paniscus). Contributors are requested to write in English and the papers except forums, reviews and essays should usually be 1,500 words or less. Articles, notes and reviews will be peer-reviewed by at least one appropriate expert on request of the $P A N$ editorial staff.

$P A N$ is published twice a year in June and December. Deadline for manuscripts is two months before publication (i.e., the ends of April and October). Submit your manuscripts via e-mail to pan.editor@gmail.com.

- Manuscripts: Format as DOC or RTF files

- Photos and figures: Format as JPEG or GIF files. Do NOT paste on Word files or create as PDF files. Figures could be sent as excel files also.

- Audiovisual data: Authors could include audiovisual data to enhance their papers, although they will be included in the online version only. Sound or video files should be sent only after communicating with the editor to obtain more detailed instructions.

- Send these separately by e-mail attachments.

See also http://mahale.main.jp/PAN/instruction.html Deadline of the next issue is April 2018!

\section{<NOTE>}

A Female Bonobo Sleeping on the Ground after

Daytime Birth and its Implications

$$
\text { Heungjin Ryu }
$$

\section{<NOTE>}

Lonoa: The Establishment of a Permanent Field

Site for Behavioural Research on Bonobos in the

Kokolopori Bonobo Reserve

Martin Surbeck, Sally Coxe, \&

Albert Lotana Lokasola

\section{<NOTE>}

Termite Fishing by Mahale Chimpanzees: Revisited, Decades Later

Alejandra Pascual-Garrido

\section{<NOTE>}

An Old Female Bonobo Carried a Dead Red-Tailed

Monkey for over a Month

Kazuya Toda, Nahoko Tokuyama, \&

Takeshi Furuichi

\section{<BOOK REVIEW>}

Cannibalism: A Perfectly Natural History (By Bill Schutt)

William C. McGrew

\section{<NOTE>}

\section{A Female Bonobo Sleeping on the Ground after Daytime Birth and its Implications}

\author{
Heungjin Ryu $u^{1,2,3}$ \\ 1 Primate Research Institute, Kyoto University, Japan \\ 2 Research Institute of Eco-science, Ewha Womans University, \\ Republic of Korea \\ 3 National Institute of Ecology, Republic of Korea \\ (Email: ryu.heungjin.26v@st.kyoto-u.ac.jp)
}

\section{INTRODUCTION}

Reduction of predation risk is thought to be one of the main benefits that animals derive from living in a group (Alexander 1974) and a major driving force in the evolution of group-living in primates (Hill \& Lee 1998). 


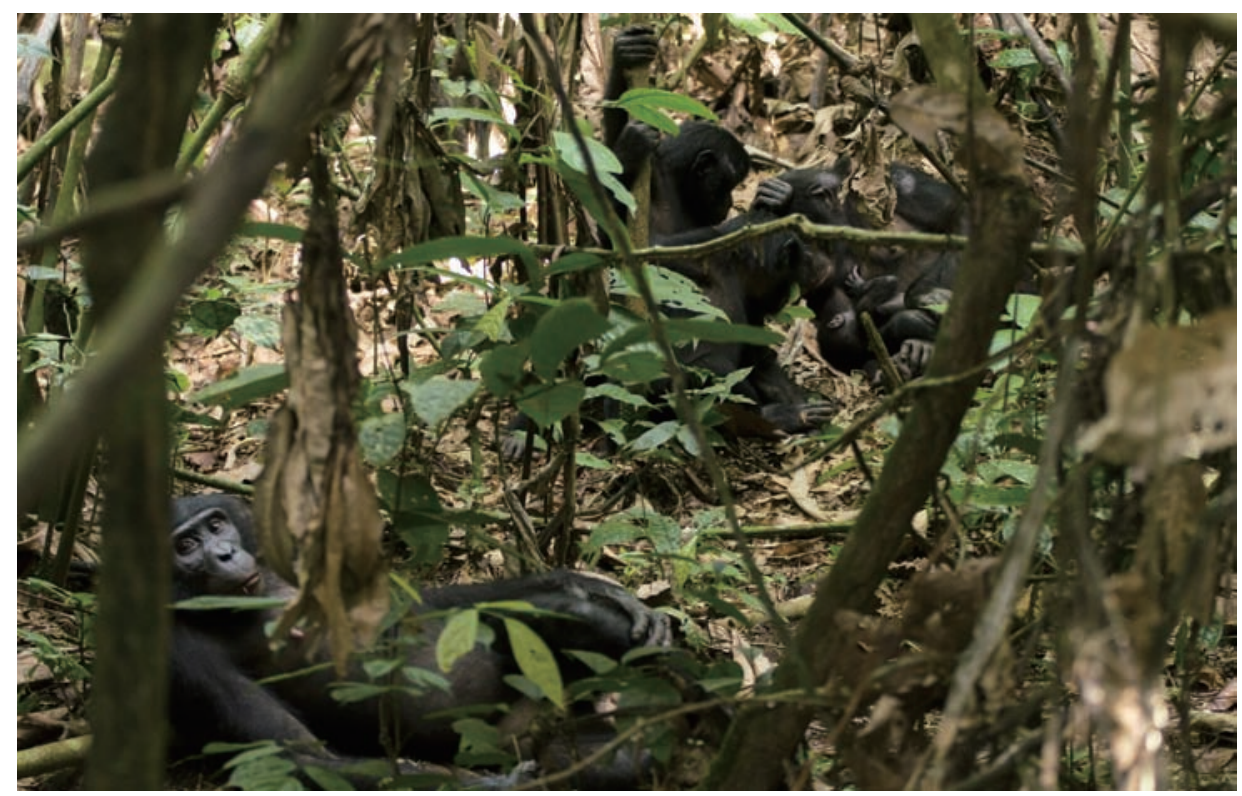

Figure 1. Ot with her newborn infant (OS) on the ground. Ok and Fa looking at OS. Fk lying about $2 \mathrm{~m}$ from the other three and looking back at human observers.

For bonobos and chimpanzees, the combined effects of large body size and group living may mean that predation risk is relatively low compared with many other primate species, but some reports have suggested that lions and leopards can have a heavy impact on them (Boesch 1991; Tsukahara 1993; D’Amour et al. 2006). Among chimpanzees there is an additional risk from conspecific killing, which is probably responsible for deaths of more infants and adults than predation itself (Williams et al. 2008).

Although they are closely related, bonobos are quite different from chimpanzees in terms of conspecific aggression and female-female relationships (Furuichi 2011). Neither direct evidence of infanticide nor conspecific killing has been observed in wild bonobos. Female chimpanzees are less tolerant and compete with each other for local resources, probably as a means to increase their reproductive success (Pusey \& Schroepfer-Walker 2013). Female bonobos, on the other hand, often engage in affiliative interactions such as grooming and homosexual interactions called genito-genital rubbing (Kuroda 1980; Ryu et al. 2015) and may support each other in response to aggression from males (Tokuyama \& Furuichi 2016). Female bonobos keep this high sociality even during one's parturition (Douglas 2014). This friendly social environment appears to influence many behavioral characteristics of female bonobos.

Here I report a case of a prime parous female bonobo giving birth in the daytime at Wamba in the Luo Scientific Reserve, Democratic Republic of the Congo. The subject female, called Otomi (Ot) gave birth on a daybed on April 5th, 2015. After giving birth, Ot came down to the ground and fell asleep while her nearest neighbor Fuku (Fk) was sitting about $2 \mathrm{~m}$ from her. I will discuss how tolerant and supportive group characteristics can be related with behavioral characteristics of female bonobos compared with that of female chimpanzees.

\section{METHODS AND BACKGROUND}

E1 group was originally one of the two subunits of E group which had been habituated by 1976 (Furuichi et al. 2012). Since then, E1 group has been studied for over 40 years at Wamba, with a break of 6 years from 1996 to 2002 because of the civil war in DR Congo. When researchers resumed the field study in 2002, all members of E1 had been re-identified and no artificial provisioning has been conducted since that time (Furuichi et al. 2012).

I followed E1 group from dawn to dusk (bed to bed) with two field assistants. We recorded all occurrences of rare behaviors, such as aggression and copulation, as well as membership of the party every hour using the 1-hour party method (Hashimoto et al. 2001).

Otomi (Ot) was one of two females that immigrated into E1 from an adjacent group in 2008, at which time she was estimated to be 11 years old (Sakamaki et al. 2015). Ot successfully gave birth to her first offspring in January 2011, and it was named Otoko (Ok; + ). Ok had grown up and become an independent individual by 2015. Ot had a still-birth in March 2014 when Ok was 3 years and 2 months old. Ot became pregnant again 5 months after the still-birth. This time Ot successfully gave birth on April 5, 2015, and this offspring was named Osamu (OS; $\widehat{\jmath})$.

Two months prior to Ot's immigration, another immigrant female Fuku (Fk) joined E1 group. Fk also gave a birth in January 2011, and her offspring was named Fua (Fa; +). The relationship between Ot and Fk was stable and strong in 2015 when the observations in this report were made.

\section{OBSERVATIONS}

At 05:31-06:00 h, April 5th, 2015, Ot was found without newborn infant at the bed site. E1 group moved into the secondary forest, where Musanga trees (Musanga cecropioides) are most abundant.

At 07:45 h, Ot stayed in a daybed and I could not detect any particular movement nor vocalization (focal sam- 
pling). The only other daybed in the same tree was Ok's, (about $2 \mathrm{~m}$ distance). Two more daybeds were around at $7 \mathrm{~m}$ from Ot's bed (individuals in them were not identified). I left the place at 08:05 $\mathrm{h}$ when the focal sampling was over.

At 08:45-08:50 h, Ot urinated on the daybed, and left. The urine found on the leaves of shrubs below included some drops of blood. Ot was carrying a newborn infant (OS) with umbilical cord (around $5 \mathrm{~cm}$ ) still attached. Ot moved into a bushy place and lay on the ground. Ok followed Ot.

At 08:51-09:22 h, Fk and Fa appeared at the place where Ot and Ok were. Fk stopped about $2 \mathrm{~m}$ from Ot. $\mathrm{Fa}$ and Ok approached within arm's reach of Ot to see OS (Figure 1, Video 1 available online at http://mahale.main. jp/PAN/24_2/24(2)_01.html). Ot sometimes shooed them away when they got too close to OS (Figure 2). Fk was watching Ot from about $2 \mathrm{~m}$ away and did not get closer. While taking a rest on the ground, Ot fell asleep and tried to open her eyes (Figure 3 and Video 1). I left with the trackers to avoid disturbing them anymore.

Ot and her two offspring were then absent from the group until April 13, 2015 (8 days). TN (an adult male; over 40 years old) was also missing from 7 th to 13 th and it may be that $\mathrm{TN}$ ranged with $\mathrm{Ot}$ and her two offspring.

\section{DISCUSSION}

After giving birth, a bonobo mother might be expected to experience sleepiness, as shown in the current report. However, sleeping on the ground will increase the risk of being attacked by predators or conspecific individuals. Therefore, it is hard to imagine that a female of a solitary primate species could fall asleep on the ground with a newborn infant. This might be also true for a female living in an intolerant social environment, such as that of chimpanzees. Female chimpanzees increase vigilance and self-directed behaviors when there are more members in close proximity (Kutsukake 2003, 2006). Moreover, other conspecifics can seriously harm one's newborn infant in chimpanzees (Goodall 1977; Nishie \& Nakamura 2018). However, if the risk of predation or harmful contact by conspecifics is very low, females might not need to maintain a high level of vigilance while they are with other group members as described in the current report.

Female bonobos maintain close social relationships with each other and support one another in agonistic interactions. These close social relationships and agonistic support enable females to maintain high social status as they are able to counter any attempts by males to dominate them (Parish 1996; Tokuyama \& Furuichi 2016). The current report is in line with these findings. If a female bonobo with other group members can benefit from their protection from predation and conspecific harassment, the need for maintaining vigilance will be low. Douglas (2014) also suggested that females get benefit of protection and relief from others during the parturition. Therefore, the cohesive grouping pattern and tolerant female-female relationship might be the medium that makes female bonobos relaxed, even at times when they are relatively vulnerable, such as immediately postpartum.

The presence of human observers is unlikely to have been a cause of Ot's post-partum sleeping. Even though bonobos of E1 group are well habituated, when human observers accidently get too close to bonobos (within about $5 \mathrm{~m}$ ), they usually move away from the human observers. Females are particularly sensitive to accidental approaches by human observers. Therefore, it seems most likely that the presence of Fk and the stable relationship between them facilitated post-partum sleeping by Ot. It is unlikely that Fk had tracked Ot's movements until she gave birth. However, given that frequent proximity and affiliative interactions between $\mathrm{Ot}$ and Fk, Fk was most likely to be the individual whom Ot would encounter for the first time after giving birth.

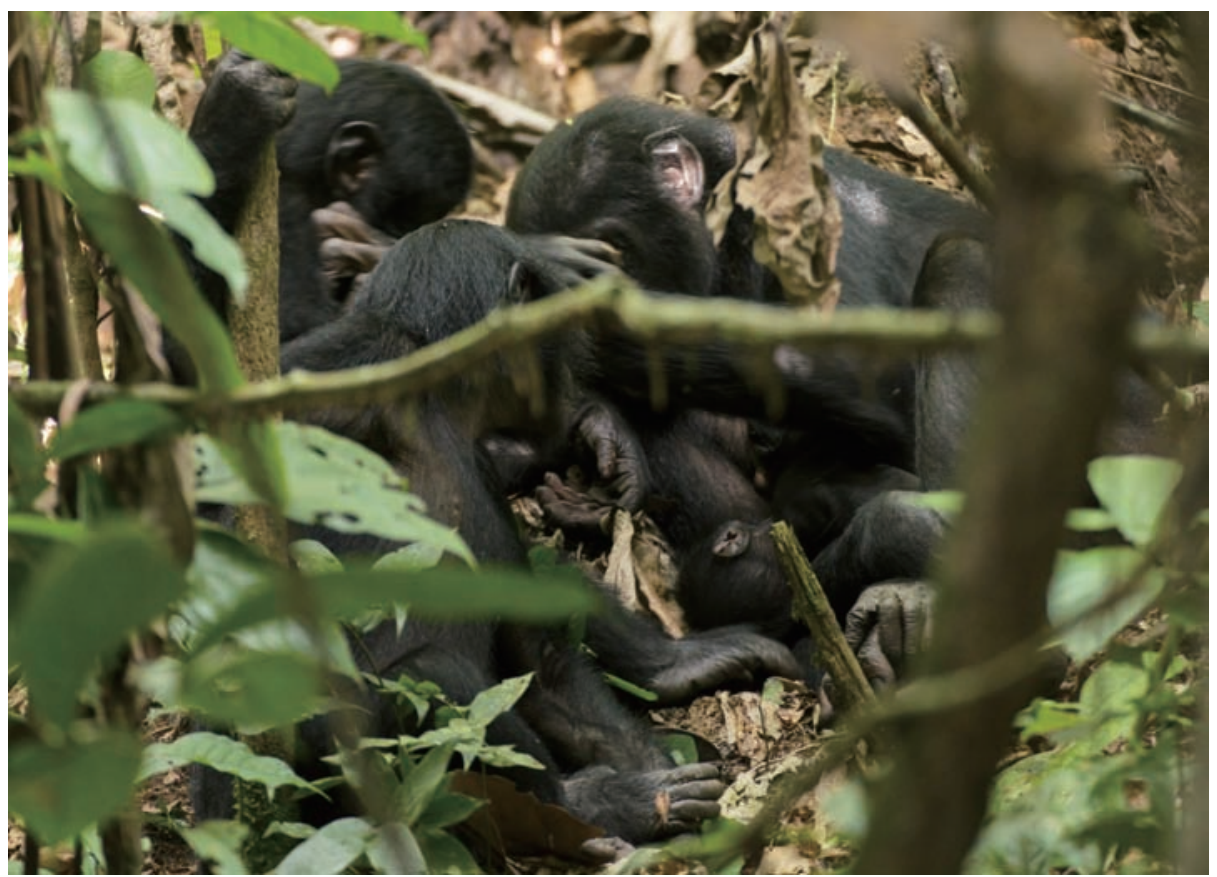

Figure 2. Ot pushing Ok away from the newborn infant, OS. 


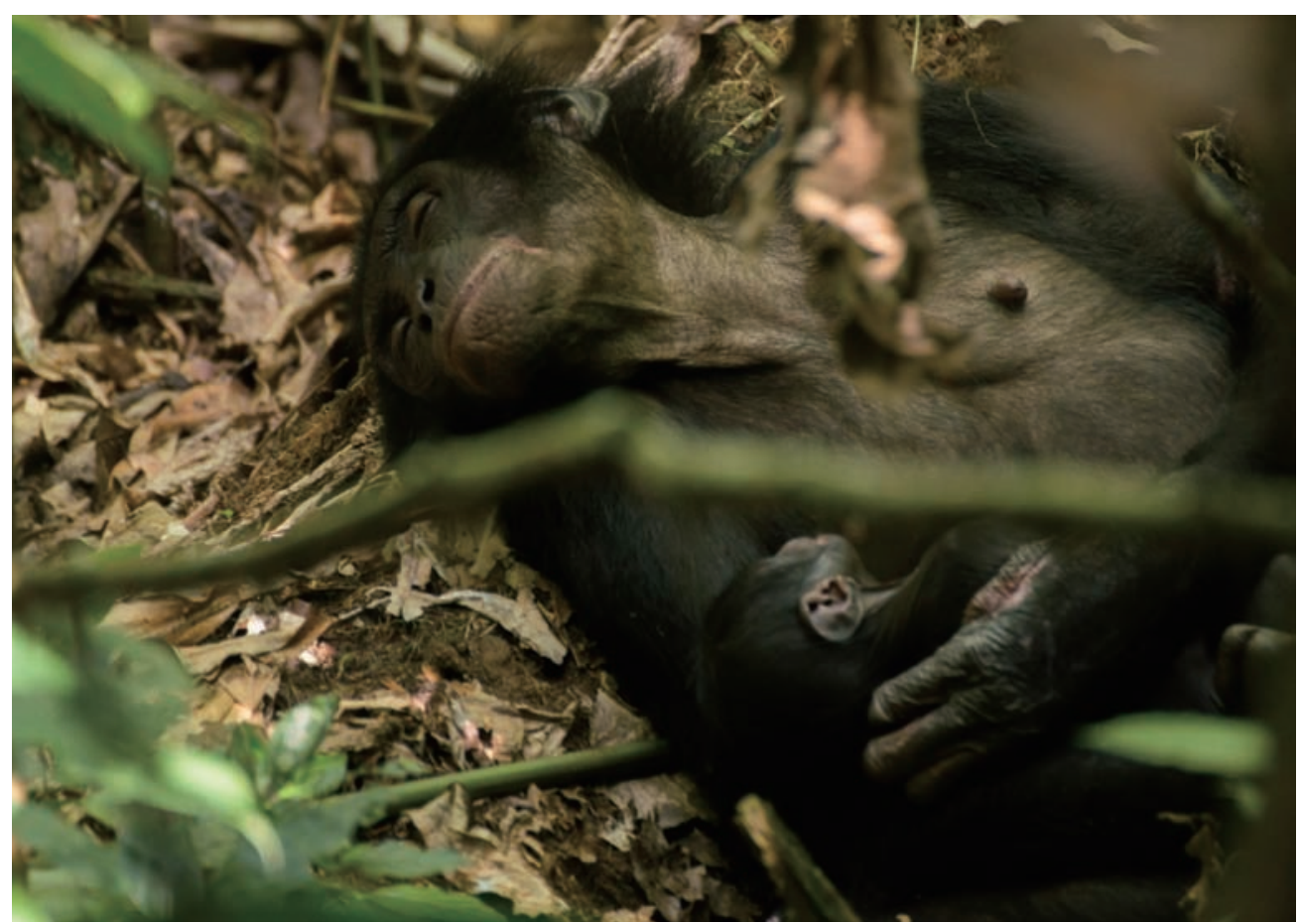

Figure 3. Ot has fallen asleep on the ground with her newborn infant (OS), while Fk, Ok, Fa stay around her within $2 \mathrm{~m}$.

Nishie \& Nakamura (2018) suggested that the temporal leaving of females after giving birth functions as "maternity leave" in chimpanzees to avoid the risk of infanticide. In the current study group (E1), females with newborn infants also range for one to two weeks alone, or only with their other offspring, immediately after giving birth. However, after one or two weeks, females usually join a party and range with group members. This is probably because the mother with a newborn infant can find fruiting trees and avoid predation risk more efficiently by ranging with other group members. Together with the fact that no infanticide has ever been reported in bonobos, the temporal leaving of female bonobos after parturition is more likely related with the cost of ranging with other group members rather than the risk of infanticide.

The tolerant group characteristics of bonobos might also allow female bonobos to exploit the benefit of group living more than female chimpanzees can do. This highlights the impact that social environment can have on behavioral characteristics of females. Further comparative studies on difference of behavioral characteristics of the two Pan species will not only help us to understand the Pan species, but may also improve our understanding of how social characteristics of various human societies influence well-being and behavioral characteristics of the individuals in them.

\section{ACKNOWLEDGEMENTS}

I thank research assistants at Wamba and the Research Center of Ecology and Forestry for their great contribution at the study site. I also thank Dr. Takeshi Furuichi, Dr. Tetsuya Sakamaki for their support. I also thank Dr. Hitonaru Nishie and Dr. Kazuhiko Hosaka for reviews on the manuscript. Finally, I thank Dr. David A. Hill for comments on the manuscript and English editing. This study was permitted by the Ministry of Scientific and Technological Research of the D.R. Congo (MIN.ESURS/SG-RST/026/2014) and funded by the
Japan Society for the Promotion of Science (JSPS) Asia-Africa Science Platform Program (2012-2014 to Furuichi).

\section{REFERENCES}

Alexander RD 1974. The evolution of social behavior. Annu Rev Ecol Syst 5:325-383.

https://doi.org/10.1146/annurev.es. 05.110174 .001545

Boesch C 1991. The effects of leopard predation on grouping patterns in forest chimpanzees. Behaviour 117:220-241. https://doi.org/10.1163/156853991X00544

D’Amour DE, Hohmann G, Fruth B 2006. Evidence of leopard predation on bonobos (Pan paniscus). Folia Primatol 77:212-217.

https:///oi.org/10.1159/0000091230

Douglas PH 2014. Female sociality during the daytime birth of a wild bonobo at Luikotale, Democratic Republic of the Congo. Primates 55:533-542. https://doi.org/10.1007/s10329-014-0436-0

Furuichi T 2011. Female contributions to the peaceful nature of bonobo society. Evol Anthropol 20:131-142. https://doi.org/10.1002/evan.20308

Furuichi T, Idani G, Ihobe H et al. 2012. Long-term studies on wild bonobos at Wamba, Luo scientific reserve, D. R. Congo: Towards the understanding of female life history in a male-philopatric species. In: Long-Term Field Studies of Primates. Kappeler PM, Watts DP (eds), Springer Berlin Heidelberg, Berlin, Heidelberg, pp. 413-433

Goodall J 1977. Infant killing and cannibalism in free-living chimpanzees. Folia Primatol 28:259-282. https://doi.org/10.1159/000155817.

Hashimoto C, Furuichi T, Tashiro Y 2001. What factors affect the size of chimpanzee parties in the Kalinzu Forest, Uganda?: Examination of fruit abundance and number of estrous females. Int J Primatol 22:947-959. https://doi.org/10.1023/A:1012061504420

Hill RA, Lee PC 1998. Predation risk as an influence on group size in cercopithecoid primates: Implications for social structure. J Zool 245:447-456. https://doi.org/10.1111/j.1469-7998.1998.tb00119x

Kuroda S 1980. Social behavior of the pygmy chimpanzees. Primates 21:181-197.

https://doi.org/10:1007/bf02374032

Kutsukake N 2003. Assessing relationship quality and social 
anxiety among wild chimpanzees using self-directed behaviour. Behaviour 140:1153-1171.

https://doi.org/10.1163/156853903322589687

Kutsukake N 2006. The context and quality of social relationships affect vigilance behaviour in wild chimpanzees. Ethology 112:581-591.

https://doi.org/10.1111/j.1439-0310.2006.01200x

Nishie H, Nakamura M 2018. A newborn infant chimpanzee snatched and cannibalized immediately after birth: Implications for "maternity leave" in wild chimpanzee. $\mathrm{Am}$ J Phys Anthropol 165:194-199.

https:///oi.org/10.1002/ajpa.23327

Parish AR 1996. Female relationships in bonobos (Pan paniscus): Evidence for bonding, cooperation, and female dominance in a male-philopatric species. Hum Nat 7:61-96. https://doi.org/10.1007/BF02733490

Pusey AE, Schroepfer-Walker K 2013. Female competition in chimpanzees. Phil Trans R Soc B 368:20130077. https://doi.org/10.1098/rstb. 2013.0077.

Ryu H, Hill DA, Furuichi T 2015. Prolonged maximal sexual swelling in wild bonobos facilitates affiliative interactions between females. Behaviour 152:285-311. https://doi.org/10.1163/1568539X-00003212

Sakamaki T, Behncke I, Laporte M et al. 2015. Intergroup transfer of females and social relationships between immigrants and residents in bonobo (Pan paniscus) societies. In: Dispersing Primate Females: Life History and Social Strategies in Male-Philopatric Species. Furuich T, Yamagiwa J, Aureli F (eds), Springer Japan, Tokyo, Japan, pp. $127-164$

Tokuyama N, Furuichi T 2016. Do friends help each other?: Patterns of female coalition formation in wild bonobos at Wamba. Anim Behav 119:27-35. https://doi.org/10.1016/j.anbehav.2016.06.021

Tsukahara T 1993. Lions eat chimpanzees: The first evidence of predation by lions on wild chimpanzees. Am J Primatol 29:1-11. https://doi.org/10.1002/ajp.1350290102

Williams JM, Lonsdorf EV, Wilson ML et al. 2008. Causes of death in the Kasekela chimpanzees of Gombe National Park, Tanzania. Am J Primatol 70:766-777. https:///oi.org/10.1002/ajp.20573

\section{<NOTE>}

\section{Lonoa: The Establishment of a Permanent Field Site for Behavioural Research on Bonobos in the Kokolopori Bonobo Reserve}

\author{
Martin Surbeck ${ }^{1,2}$, Sally Coxe ${ }^{2}, \&$ \\ Albert Lotana Lokasola ${ }^{2,3}$ \\ 1 Max-Planck-Institute for Evolutionary Anthropology, \\ D-04103 Leipzig, Germany \\ 2 Bonobo Conservation Initiative, 2701 Connecticut Ave. NW, \\ Suite 702, Washington DC 20008, US \\ 3 Vie Sauvage, Avenue Pangi 5, commune Ma Campagne, \\ Kinshasa, DRC \\ (E-mail: surbeck@eva.mpg.de)
}

The Kokolopori Bonobo Reserve was officially established by the Democratic Republic of the Congo (DRC) government in May 2009 as a community-based nature reserve encompassing over $4,850 \mathrm{~km}^{2}$ (Almquist et al. 2010; Figures 1 and 2). Locally initiated and managed, it harbors a large population of bonobos, who are and have been traditionally protected by a taboo of the local Bongando people against hunting them (Lingomo \& Kimura 2009). The management of the reserve is conducted by the local population and the conservation initiative "Vie Sauvage" (VS), supported by the Bonobo Conservation Initiative (BCI).

Efforts to follow bonobos in the northern part of the reserve, near the village of Yetee, were initiated in 2005 by VS and BCI, which had been committed to establishing longitudinal research on bonobos and had commenced ongoing support of local people to track the Ekalakala bonobo community (Figure 2). In 2010, the tracking extended to a second, neighboring bonobo community, Nkokoalongo. Until 2016, both communities had been followed on a more or less regular schedule, but were subject to only a limited amount of formal scientific work. Dr. Alex Georgiev did some work in the ranging area of the Ekalakala community, collecting fecal samples during 2006 and 2007. These samples were included in a number of publications on malaria and micro biome (Liu et al. 2010; Liu et al. 2014; Ahuka-Mundeke et al. 2016; Moeller et al. 2016; Wroblewski et al. 2017). Dr. Deborah Moore commenced behavioural ecological research at the site in 2014 with the intention of establishing a longitudinal study, but unfortunately was curtailed after 4 months. During her stay, she reorganized the habituation procedure for both communities and made some initial behavioural observations, including an incidence of maternal cannibalism (Tokuyama et al. 2017).

After MS's reconnaissance trip in 2015, he established a permanent research camp named after the nearby river, Lonoa $\left(\mathrm{N} 0.41716^{\circ}, \mathrm{E} 22.97552^{\circ}\right)$, in the beginning of 2016 with the help of the Max Plank Institute, VS and BCI. The camp is situated approximately $4 \mathrm{~km}$ from the nearest village, Yetee (Figure 1). A network of existing paths and standardized transects allows access to an area of $50 \mathrm{~km}^{2}$, which comprises large parts of the ranges of the two habituated bonobo communities. The study area consists mainly of primary heterogeneous forest with very few swampy areas. The bonobos of the Ekalakala community also range occasionally in secondary forests close to the local settlements. An initial botanical survey to describe the forest types and composition has been con-

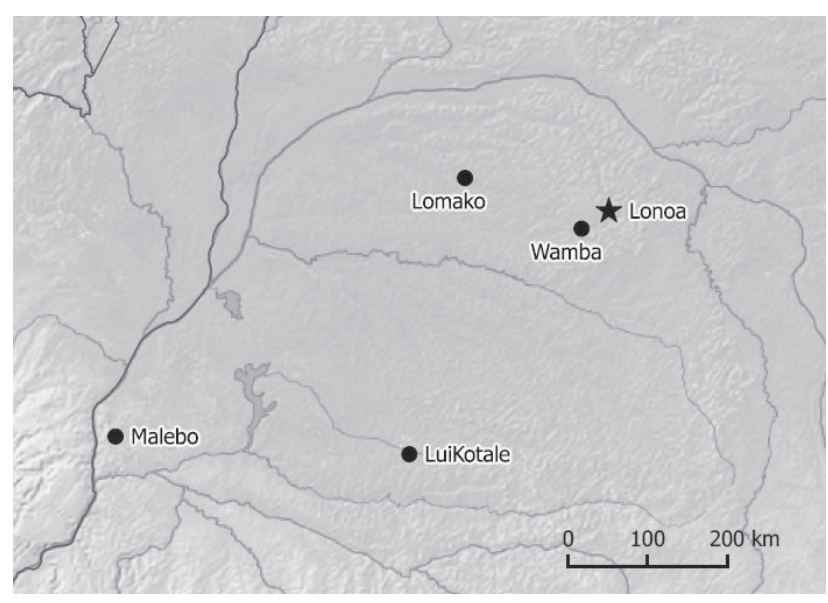

Figure 1. Active bonobo research sites with at least semihabituated bonobo communities. 